\title{
OPTIMASI PEMBUATAN DIETIL ETER DENGAN PROSES REAKTIF DISTILASI
}

\author{
Widayat $^{*}$ dan Hantoro Satriadi \\ Jurusan Teknik Kimia Fakultas Teknik UNDIP Semarang \\ Jl. Prof. Soedarto, SH, Tembalang, Semarang 50239, Telp.(024)7460058 \\ ${ }^{*}$ Penulis korespondensi: yayat_99@yahoo.com
}

\begin{abstract}
Abstrak
DiEtil Eter banyak digunakan sebagai bahan pelarut untuk reaksi organik dan pemisahan senyawa organik dari sumber alamnya, sebagai bahan bakar. DiEtil Eter umumnya diproduksi dengan proses dehidrasi etanol dengan katalis asam sulfat pada suhu $125^{\circ} \mathrm{C}-140^{\circ} \mathrm{C}$ (proses barbet). Penelitian ini bertujuan untuk memperoleh kondisi optimum pada pembuatan dietil eter dengan katalis asam sulfat dan proses reaktif distilasi. Variabel yang dioptimasi adalah konsentrasi asam sulfat awal dan perbandingan mol reaktan etanol dengan asam sulfat. Proses optimasi menggunakan metode respon permukaan dan pengolahan data dengan perangkat lunak Statistica ${ }^{(R)}$. Proses pembuatan dietil eter dilakukan pada volume $700 \mathrm{ml}$, waktu 100 menit dan suhu operasi $125-130^{\circ}$ C. Hasil penelitian menunjukkan bahwa model matematika yang diperoleh hubungan konversi etanol dengan perbandingan mol reaktan etanol dengan asam sulfat dan konsentrasi awal asam sulfat adalah $Y=-919,57+163,18 X_{1}+153,57 X_{2}-29,517 X_{1}^{2}-6,549 X_{2}^{2}-7,53 X_{1} X_{2}$. Konversi etanol optimum sebesar 31,83\% pada kondisi operasi perbandingan mol reaktan etanol dengan asam sulfat $1: 1,30$ dan konsentrasi awal asam sulfat 10,98 M.
\end{abstract}

Kata kunci: asam sulfat, dietil eter, konversi etanol, reaktif distilasi

\begin{abstract}
Diethyl Ether can be used as solvent in organic reaction and separation organic compound from natural resources and as fuel. Diethyl Ether compound commonly produced by using ethanol dehydration process with sulfuric acid as catalyst (barbet process). This process did at $125^{\circ} \mathrm{C}-140^{\circ} \mathrm{C}$ temperature. The objective of this research is for found optimum condition in Diethyl Ether production with reactive distillation process. The parameters optimized sulfuric acid initial concentration and ratio ethanol and sulfuric acid (mole/mole). The optimization process use central composite design or surface response methodology. The analysis of data by using Statistica ${ }^{(R)}$ sofware. Diethyl Ether production process was did in $700 \mathrm{ml}$, with time operation 100 minutes and operation temperature $125-130^{\circ}$ C. The mathematical model for relation of ethanol conversion with ratio of ethanol with sulfuric acid (mole/mole) $\left(X_{1}\right)$ and sulfuric acid initial concentration $\left(X_{2}\right)$ is $Y=-919,57+163,18 X_{1}+153,57 X_{2}-29,517 X_{1}^{2}-6,549 X_{2}^{2}-7,53 X_{1} X_{2}$. The ethanol conversion optimum obtained $31.83 \%$ while the conditions operation were $1: 1,30$ for ratio of ethanol with sulfuric acid (mole/mole) and 10,98 M sulfuric acid initial concentration.
\end{abstract}

Key words: sulfuric acid, Diethyl Ether, ethanol conversion, reactive distillation

\section{PENDAHULUAN}

DiEtil Eter merupakan salah satu dari eter komersial yang paling penting diantara eter yang lainnya. Dalam industri dietil eter banyak digunakan sebagai bahan pelarut untuk melakukan reaksi-reaksi organik dan memisahkan senyawa organik dari sumber alamnya. Penggunaan sebagai pelarut diantaranya untuk pelarut minyak, lemak, getah, resin, mikroselolosa, parfum, alkaloid, dan sebagian kecil dipakai dalam industri butadiena. Di dalam dunia kedokteran dietil eter sangat di identikkan sebagai bahan anestesi (Ulmann, 1987). Eter merupakan senyawa yang dapat di manfaatkan untuk meningkatkan bilangan oktan dalam bahan bakar premium. Diantara jenis eter yang biasa dimanfaatkan untuk meningkatkan bilangan oktan adalah MTBE (Methyl Tertiary Buthyl Ether) dan ETBE (Ethyl Tertiary Buthyl Ether). Senyawa dietil eter akhir-akhir ini mulai dimanfaatkan sebagai 
pengungkit bilangan setana pada bahan bakar diesel atau biodiesel, karena mempunyai bilangan setana yang tinggi.

Eter adalah senyawa tak berwarna dengan bau enak yang khas. Titik didihnya rendah dibanding alkohol dengan jumlah atom karbon yang sama, dan kenyataannya mempunyai titik didih sama dengan hidrokarbon, dimana pada eter gugus $-\mathrm{CH}_{2}$ - digantikan oleh oksigen. DiEtil Eter mmempunyai rumus bangun sebagai berikut $\mathrm{CH}_{3} \mathrm{CH}_{2}-\mathrm{O}-\mathrm{CH}_{2} \mathrm{CH}_{3}$. (Fessenden and Fessenden, 1997). Hal ini seperti disjaikan dalam tabel 1 berikut.

Tabel 1. Sifat fisik eter terhadap etanol dan hidrokarbon

\begin{tabular}{llcc}
\hline Nama & \multicolumn{1}{c}{ Rumus } & $\begin{array}{c}\text { Titik } \\
\text { didih } \\
\left({ }^{0} \mathrm{C}\right)\end{array}$ & $\begin{array}{c}\text { Bobot } \\
\text { mol }\end{array}$ \\
\hline 1-butanol & $\mathrm{CH}_{3} \mathrm{CH}_{2} \mathrm{CH}_{2} \mathrm{CH}_{2} \mathrm{OH}$ & 178 & 74 \\
dietil eter & $\mathrm{CH}_{3} \mathrm{CH}_{2}-\mathrm{O}_{-} \mathrm{CH}_{2} \mathrm{CH}_{3}$ & 35 & 74 \\
pentana & $\mathrm{CH}_{3} \mathrm{CH}_{2}-\mathrm{CH}_{2}-$ & 36 & 72 \\
& $\mathrm{CH}_{2} \mathrm{CH}_{3}$ & & \\
\hline
\end{tabular}

DiEtil Eter dapat diproduksi dengan proses dehidrasi etanol pada fase uap dalam reaktor unggun tetap dengan katalis alumina. Namun kebanyakan industri memproduksi dietil eter dengan dehidrasi etanol menggunakan asam sulfat pada suhu $125^{\circ} \mathrm{C}-140^{\circ} \mathrm{C}$ (proses barbet) (Kirk-Othmer, 1965). Reaksi yang terjadi adalah sebagai berikut:

$$
2 \mathrm{C}_{2} \mathrm{H}_{5} \mathrm{OH}_{(\mathrm{l})} \underset{25^{0}-145^{0} \mathrm{C}}{\stackrel{\mathrm{H}_{2} \mathrm{SO}_{4}}{\longrightarrow}} \mathrm{C}_{2} \mathrm{H}_{5} \mathrm{OC}_{2} \mathrm{H}_{5(\mathrm{l})}+\mathrm{H}_{2} \mathrm{O}_{(\mathrm{l})}
$$

dengan mekanismenya sebagai berikut :

$$
\begin{aligned}
& \mathrm{C}_{2} \mathrm{H}_{5} \mathrm{OH}+\mathrm{H}_{2} \mathrm{SO}_{4} \longrightarrow \mathrm{C}_{2} \mathrm{H}_{5} \mathrm{HSO}_{4}+\mathrm{H}_{2} \mathrm{O} \\
& \mathrm{C}_{2} \mathrm{H}_{5} \mathrm{OH}+\mathrm{C}_{2} \mathrm{H}_{5} \mathrm{HSO}_{4} \longrightarrow \mathrm{C}_{2} \mathrm{H}_{5} \mathrm{OC}_{2} \mathrm{H}_{5}+\mathrm{H}_{2} \mathrm{SO}_{4}
\end{aligned}
$$

Dalam mekanisme reaksi tersebut, menunjukkan bahwa gugus etil $\mathrm{C}_{2} \mathrm{H}_{5}$ dari etanol akan mengikat gugus $\mathrm{SO}_{4}^{-2}$ dari $\mathrm{H}_{2} \mathrm{SO}_{4}$ membentuk etil sulfat $\mathrm{C}_{2} \mathrm{H}_{5} \mathrm{HSO}_{4}$ dan senyawa $\mathrm{H}_{2} \mathrm{O}$ terbentuk dari gugus $\mathrm{OH}^{-}$etanol dengan gugus $\mathrm{H}^{+}$asam sulfat. Etil sulfat yang terbentuk akan bereaksi dengan etanol kembali membentuk dietil eter dan asam sulfat. Dari reaksi ini pula dapat dilihat bahwa asam sulfat merupakan katalis meskipun kebutuhannya cukup banyak, karena asam sulfatnya terbentuk kembali (Fessenden and Fessenden, 1997).

Proses barbet mempunyai kelemahan dalam pemisahan katalis. Hal ini dikarenakan, sifat katalis asam sulfat yang homogen. Katalis ini juga bersifat korosif. Dengan demikian membutuhkan investasi yang mahal.

Proses reaktif destilasi merupakan proses dimana reaktan direaksikan dan komponen-komponen hasil langsung dipisahkan. Dengan proses reaktif destilasi dapat menghemat biaya investasi dan memperoleh kemurnian produk yang lebih tinggi. Beberapa senyawa yang selama ini sudah diproduksi dengan proses reaktif destilasi dan memberikan keuntungan yang cukup besar adalah Metil asetat dan Metyl Tertier Butyl Ether (MTBE) (Taylor dan Krishna, 2000). Dalam proses pembuatan dietil eter dari etanol dengan katalis asam sulfat, menghasilkan senyawa dietil eter, etanosulfat. Senyawa dietil eter mempunyai titik didih yang sangat rendah dibandingkan komponen yang ada di dalamnya. Dengan demikian memungkinkan untuk membuat dietil eter dengan proses reaktif distilasi.

Widayat dan Satriadi (2005) telah melakukan penelitian pembuatan dietil eter dengan menggunakan proses reaktif distilasi. Hasil penelitian menunjukkan bahwa proses reaktif distilasi dapat digunakan untuk pembuatan senyawa dietil eter, yang ditunjukkan pada produk atas yang sebagian besar merupakan senyawa dietil eter. Dalam penelitian ini, dilakukan proses optimasi pada pembuatan senyawa dietil eter dengan proses reaktif distilasi. Penelitian ini bertujuan untuk mengoptimasi proses pembuatan dietil eter dari etanol teknis dan asam sulfat dengan proses reaktif distilasi secara batch. Variabel yang dioptimasi adalah konsentrasi awal asam sulfat dan perbandingan mol reaktan etanol dengan asam sulfat. Metode optimasi menggunakan metode respon permukaan.

\section{METODE PENELITIAN}

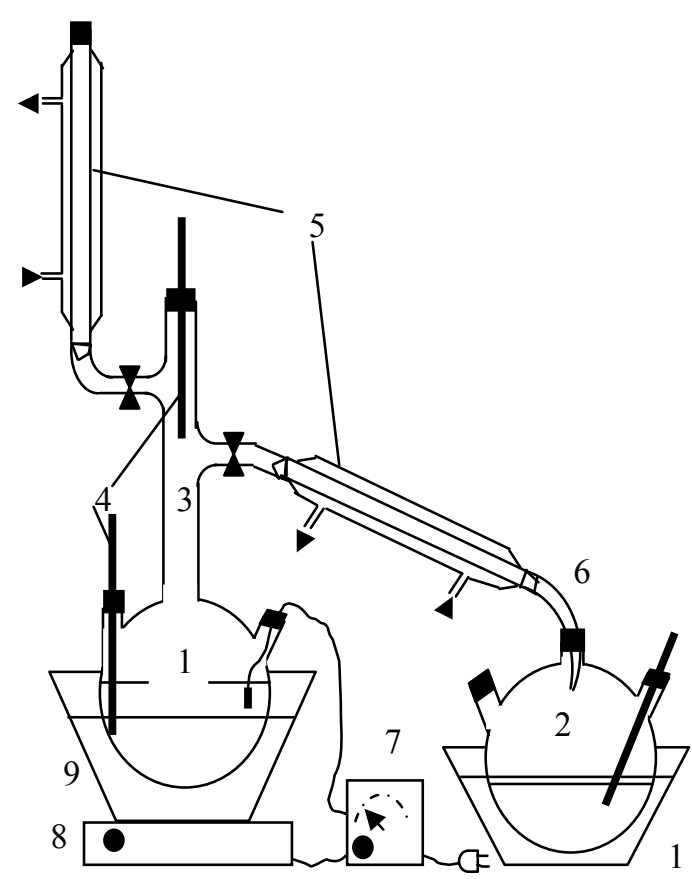

Keterangan :
1. Labu umpan
6. Adaptor
2. Labu distilat/produk
7. Kontroller suhu
3. Kolom distilasi
8. Kompor listrik
4. Termometer
9. Oil bath
5. Kondensor
10. Wadah pendingin

Gambar 1. Rangkaian alat percobaan untuk proses reaktif-distilasi 
Bahan-bahan kimia seperti asam sulfat, etanol teknis (konsentrasi 95\%), indikator $\mathrm{MO}$, oil bath membeli di Toko Kimia Indrasari. Alat yang dipakai pada penelitian ini terdiri dari rangkaian alat reaktif distilasi. Rangkaian alat utama untuk percobaan seperti disajikan di gambar 1.

Peralatan terdiri dari reaktor yang berbentuk labu leher tiga, kolom pemisahan/distilasi, pendingin produk, dan penampung produk. Respon yang dianalisa adalah kandungan dietil eter dalam produk yang dianalisa dengan gas kromatografi (GC). Data-data yang diperoleh selanjutnya diolah dengan perangkat lunak Statistica $6^{(\mathrm{R})}$. Design percobaan seperti disajikan dalam tabel 2, dimana design percobaan ini juga diperoleh dari perangkat lunak Statistica 6.

Tabel 2. Design penelitian untuk optimasi dengan metode respon permukaan

\begin{tabular}{cccccc}
\hline RUN & $\mathrm{X}_{1}$ & $\mathrm{X}_{2}$ & $\mathrm{X}_{1}$ & $\mathrm{X}_{2}$ & Respon \\
\hline 1 & +1 & -1 & 1 & 10 & $\mathrm{Y}_{1}$ \\
2 & -1 & -1 & 1 & 12 & $\mathrm{Y}_{2}$ \\
3 & +1 & +1 & 2 & 10 & $\mathrm{Y}_{3}$ \\
4 & -1 & +1 & 2 & 12 & $\mathrm{Y}_{4}$ \\
5 & 0 & 0 & 1,5 & 11 & $\mathrm{Y}_{5}$ \\
6 & 0 & 0 & 1,5 & 11 & $\mathrm{Y}_{6}$ \\
7 & $-\sqrt{ } 2$ & 0 & 1,5 & 9,6 & $\mathrm{Y}_{7}$ \\
8 & $+\sqrt{ } 2$ & 0 & 1,5 & 12,4 & $\mathrm{Y}_{8}$ \\
9 & 0 & $-\sqrt{ } 2$ & 0,8 & 11 & $\mathrm{Y}_{9}$ \\
10 & 0 & $+\sqrt{ } 2$ & 2,2 & 11 & $\mathrm{Y}_{10}$ \\
\hline
\end{tabular}

Keterangan :

$\mathrm{R}$ : Perbandingan mol reaktan etanol dengan asam sulfat $\mathrm{C}$ asam: Konsentrasi Asam sulfat

+1 : nilai atas ,

-1 : nilai bawah,

0 : nilai tengah

$+\sqrt{2}$ : nilai kritis atas

$-\sqrt{2}$ : nilai kritis bawah

Untuk memperoleh nilai parameter kondisi operasi dapat dihitung menggunakan persamaan 1 dan 2 atau dengan memasukkan nilai batas atas dan bawah ke dalam perangkat lunak Statistica 6 .

$$
\begin{gathered}
X_{1}=\frac{R-1,5}{0,5} \\
X_{2}=\frac{C \text { asam }-11 M}{1 \mathrm{M}}
\end{gathered}
$$

Percobaan dilakukan dengan memasukkan etanol dan $\mathrm{H}_{2} \mathrm{SO}_{4}$ kedalam labu umpan distilasi. Reaksi dilangsung pada ondisi titik didihnya. Produk dan komponen-komponen ringan akan menguap. Uap akan berkontak dengan kondensat dalam kolom distilasi dan terbentuk kesetimbangan. Etanol dan air yang mempunyai titik didih lebih tinggi dari dietil eter akan terkondensasi dan kembali kebawah. Proses pembentukan kesetimbangan juga dapat terbentuk dengan pendinginan dari udara luar. Suhu pada puncak distilasi dijaga dibawah $78^{\circ} \mathrm{C}$. Pencapaian suhu operasi tersebut membutuhkan waktu \pm 30 menit. Produk dietil eter akan mengalir ke labu distilat/produk melewati kondensor sehingga terkondensasi dan suhunya akan turun yaitu mencapai $+33^{\circ} \mathrm{C}$ (dijaga agar dibawah $35^{\circ} \mathrm{C}$ ). Dalam labu distilat/produk didinginkan dengan pendingin es yang berfungsi untuk menjaga dietil eter yang sudah tidak dapat larut dalam air tidak menguap. Suhu produk dalam labu distilat $\pm 10^{\circ} \mathrm{C}$, dimana pada suhu tersebut diharapkan tidak ada dietil eter yang menguap. Produk dianalisa dengan alat gas kromatografi.

\section{HASIL DAN PEMBAHASAN}

Hasil penelitian yang diperoleh seperti disajikan dalam tabel 3 yang merupakan perbandingan hasil percobaan dan hasil perhitungan dengan model. Model matematika yang diperoleh adalah sebagai berikut;

$$
\begin{aligned}
& Y=-919,57+163,18 X_{1}+153,57 X_{2}-29,517 X_{1}^{2} \\
& -6,549 X_{2}^{2}-7,53 X_{1} X_{2}
\end{aligned}
$$

Keterangan:

$\mathrm{X}_{1}$ dan $\mathrm{X}_{2}$ mengikuti Persamaan 1 dan 2

$\mathrm{Y}$ adalah konversi pembentukan dietil eter

Tabel 3. Hasil penelitian dari percobaan dan hasil perhitungan dari model

\begin{tabular}{ccccc}
\hline RUN & $\mathrm{X}_{1}$ & $\mathrm{X}_{2}$ & $\begin{array}{c}\text { Hasil } \\
\text { percobaan } \\
(\mathrm{Yo})\end{array}$ & $\begin{array}{c}\text { Hasil } \\
\text { perhitungan } \\
(\mathrm{Yp})\end{array}$ \\
\hline 1 & 1 & 10 & 21,9554 & 19,593 \\
2 & 1 & 12 & 29,5945 & 23,517 \\
3 & 2 & 10 & 16,1992 & 18,922 \\
4 & 2 & 12 & 8,77037 & 7,786 \\
5 & 1,5 & 11 & 36,0774 & 31,383 \\
6 & 1,5 & 11 & 26,77542 & 31,383 \\
7 & 1,5 & 9,6 & 21,98176 & 21,071 \\
8 & 1,5 & 12,4 & 11,57806 & 16,023 \\
9 & 0,8 & 11 & 23,14219 & 31,842 \\
10 & 2,2 & 11 & 13,03998 & 11,179 \\
\hline
\end{tabular}


Hasil pada tabel 3 selanjutnya dianalisa untuk mengetahui signifikansi dan akurasi dari persamaan tersebut dilakukan analisa variasinya. Analisa variasi juga menggunakan perangkat lunak Statistica. Hasil analisa variasi seperti disajikan dalam tabel 4.

Tabel 4. Hasil Analisa ANOVA

\begin{tabular}{cccccc}
\hline & SS & df & MS & F & p \\
\hline $\begin{array}{c}\text { (1)Var1 } \\
\text { (L) }\end{array}$ & 26,2902 & 1 & 26,2902 & 1,098 & 0,35377 \\
$\begin{array}{c}\text { Var1 } \\
\text { (Q) }\end{array}$ & 217,6102 & 1 & 217,6102 & 9,0915 & 0,039348 \\
$\begin{array}{c}\text { (2)Var2 } \\
\text { (L) }\end{array}$ & 208,7679 & 1 & 208,7679 & 8,7221 & 0,041831 \\
$\begin{array}{c}\text { Var2 } \\
\text { (Q) }\end{array}$ & 178,2252 & 1 & 178,2252 & 7,4461 & 0,052511 \\
$\begin{array}{c}\text { 1L by } \\
\text { 2L }\end{array}$ & 56,7687 & 1 & 56,7687 & 2,3717 & 0,198392 \\
Error & 95,7418 & 4 & 23,9354 & & \\
Total & 665,6846 & 9 & & & \\
SS & & & & & \\
\hline
\end{tabular}

Hasil analisa varian dan variasi (anova) diperoleh MS residual $\left(\mathrm{R}^{2}\right)$ sebesar 0,85618 yang mengindikasikan bahwa $85,6 \%$ dari jumlah variasi yang sesuai dengan model. Kebenaran dari fitting model diuji dengan persamaan 1 menggunakan static Fisher $(F)$. Nilai $F$ perhitungan dibandingkan dengan nilai $\mathrm{F}_{(\mathrm{p}-1, \mathrm{~N}-\mathrm{p}, \dot{\alpha}}$ ) dari tabel untuk masing masing faktor adalah :

- $\quad$ Nilai $F_{(1) \text { reaktan1(L) }}=1,098381$ kurang dari harga dari tabel $F(1,4,0,05)=7,71$ yang berarti varian menerima null hypothesis $\left(\mathrm{H}_{0}\right)$.

- $\quad$ Nlai $\mathrm{F}_{\text {Reaktan1(Q) }}=$ 9,091549 lebih dari harga dari tabel $\mathrm{F}(1,4,0,05)=7,71$ yang berarti varian menolak null hypothesis $\left(\mathrm{H}_{0}\right)$.

- $\quad$ Nilai $F_{(2) \text { katalis2(L) }}=7,4460784$ lebih dari harga dari tabel $\mathrm{F}(1,4,0,05)=7,71$ yang berarti varian menolak null hypothesis $\left(\mathrm{H}_{0}\right)$.

- $\quad$ Nilai $\mathrm{F}_{1 \mathrm{~L} \text { by } 2 \mathrm{~L}}=2,371742$ kurang dari harga dari tabel $\mathrm{F}(1,4,0,05)=7,71$ yang berarti varian menerima null hypothesis $\left(\mathrm{H}_{0}\right)$.

Secara keseluruhan dapat diambil kesimpulan bahwa varian bersifat heterogen.

Setiap nilai hasil penelitian pengamatan (Yo), dibandingkan dengan nilai hasil prediksi (Yp) yang dihitung dari model seperti yang digambarkan pada gambar 2. Gambar 2 menunjukan bahwa sebagian besar data terletak yang tidak pada garis. Hal menunjukkan bahwa data-data hasil percobaan dengan model yang kurang valid.

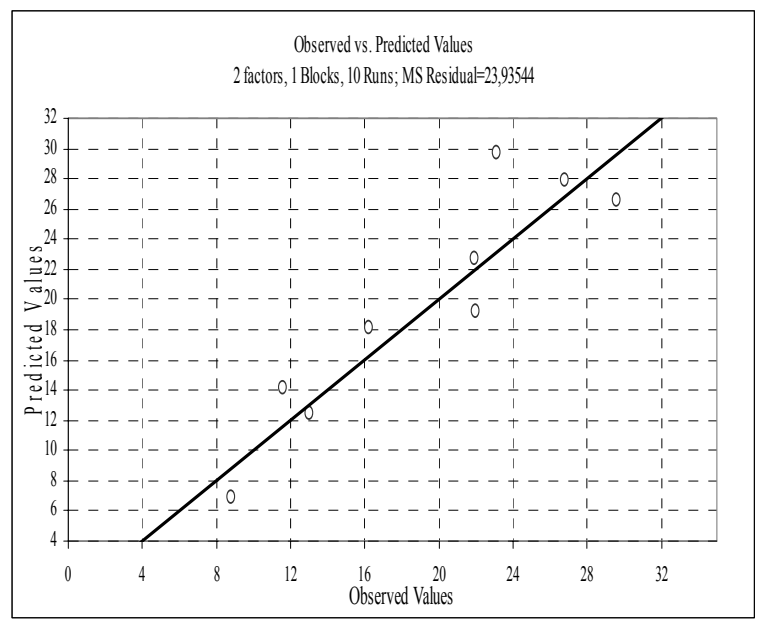

Gambar 2. Grafik perbandingan antara prediksi dengan hasil penelitian

Hasil penelitian juga disajikan dalam bentuk diagram tiga dimensi, dan hasil penelitian seperti disajikan dalam gambar 3 .

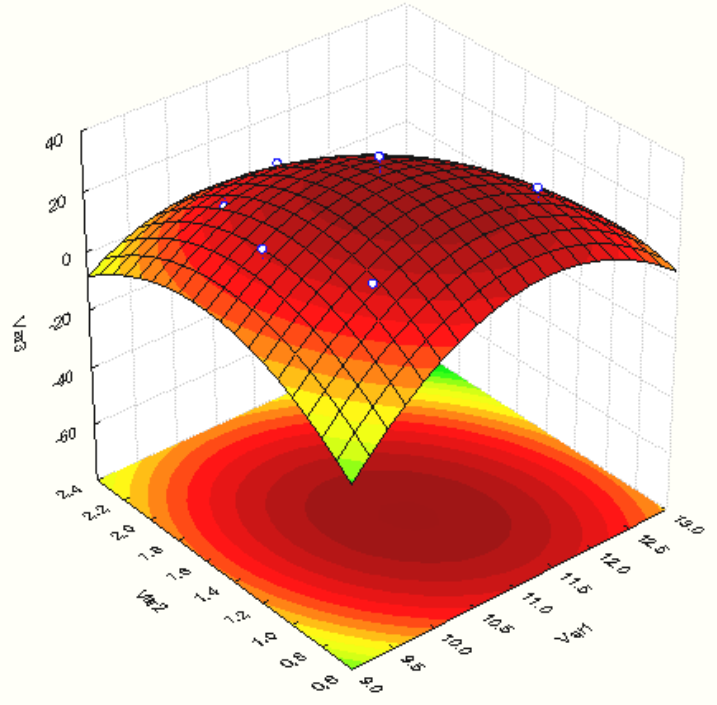

Gambar 3. Profil response fitted surface terhadap konversi pembentukan dietil eter

Hasil analisa dari model empiris diatas didapatkan kondisi operasi optimum, pada kondisi perbandingan mol reaktan $1: 1,30$ dan konsentrasi asam sulfat 10,93 M. Data-data tersebut dimasukkan ke model matematika (Persamaan 1) diperoleh nilai konversi sebesar $31,83 \%$. Secara teoritis semakin besar perbandingan mol reaktan etanol dan $\mathrm{H}_{2} \mathrm{SO}_{4}$ maka konversi yang dihasilkan akan semakin besar. $\mathrm{Hal}$ ini disebabkan karena semakin tinggi mol $\mathrm{H}_{2} \mathrm{SO}_{4}$ maka kemungkinan terkonversinya etanol menjadi dietil eter besar. Fenomena yang sama juga terjadi untuk konsentrasi katalis. Semakin tinggi konsentrasi katalis maka konversi reaksi semakin besar karena dengan tingginya konsentrasi katalis maka 
kemungkinan kontak antar molekul menjadi lebih besar. Namun dari grafik dapat dilihat bahwa titik perbandingan mol reaktan 1 : 1,30 dan konsentrasi katalis 10,93 merupakan konversi optimum dimana peningkatan setelahnya akan menurunkan konversi reaksi. Hal ini disebabkan karena proses reaktif destilasi sangat berhubungan dengan titik didih campuran. Reaksi dehidrasi ethanol menjadi dietil eter terjadi pada suhu $130^{\circ} \mathrm{C}$ (Ullman, 1987). Dengan demikian konversi reaksi akan besar pada saat titik didih campuran berada disekitar suhu reaksi, dengan penambahan $\mathrm{H}_{2} \mathrm{SO}_{4}$ dan konsentrasi asam sulfat yang tinggi, akan mempengaruhi titik didih campuran secara signifikan yang mengakibatkan volume destilat kecil dan konversi reaksi kecil.

Konversi reaksi yang kecil sangat mungkin, disebabkan oleh kondisi temperatur pada puncak distilasi yang bervariasi. Hal ini dikarenakan kesulitan mempertahankan temperatur kolom distilasi tetap pada temperatur di bawah $78^{\circ} \mathrm{C}$. Jika dilihat titik didih dietil eter yang rendah, bisa jadi banyak dietil eter yang menguap ke atas (tidak masuk sebagai distilat).

\section{KESIMPULAN}

Hasil penelitian dapat disimpulkan bahwa model matematika yang diperoleh adalah $Y=-919,57+163,18 X_{1}+153,57 X_{2}-29,517 X_{1}^{2}-6,549 X_{2}^{2}-7,53 X_{1} X_{2}$ yang bersifat heterogen. Hasil analisa dari model empiris di atas didapatkan kondisi operasi optimum, pada kondisi perbandingan mol reaktan 1 : 1,30 dan konsentrasi asam sulfat 10,93 M. Nilai konversi yang diperoleh sebesar $31,83 \%$.

\section{UCAPAN TERIMA KASIH}

Penulis mengucapkan terima kasih kepada laboratorium Kimia Analisa Fakultas MIPA yang telah membantu analisa senyawa dietil eter dengan kromatografi gas.

\section{DAFTAR PUSTAKA}

Box, Hunter and Hunter, (1981),"Statistics for Experimenters”, John Willey and Sons, New York

Fessenden, Ralp J, dan Joan S, Fessenden, (1997), "Kimia Organik", jilid 1 edisi ketiga, terjemahan oleh: Aloysius H, P, Penerbit Erlangga, Jakarta.

Gonzalez, J.C., and Fair, J.R., (1997),’Preparation og tertiary amyl alcohol in a reactive distillation column 1 , Reaction kinetics, chemical equilibrium, and masstransfer issues", Ind. and Eng Che. Res., 36 pp 38333844

Kick-Othmer, (1965), "Encyclopedia of Chemical Technology", Vol, 8, $3^{\text {rd }}$ edition, John Wiley and Sons, Inc,, United States of Amerika.

Siirola, J. J, (1995), “An Introduction perspective on process synthesis", AIChE Symposium Series No, 304 Vol, 91 pp 222 -233

Towler, G.P, and Frey, S.J., (2000), "Reactive distillation" in S, Kulprathiapanja, Reactive separation processes, Philadelphia Taylor and francis

Taylor, R, dan R, Krishna, (2000), "Modeling Reactive Distillation", Chemical Engineering Science, Pergamon,

Ullmann, (1987), "Encyclopedia of Industrial Chemistry", Vol, A.10, $5^{\text {th }}$ edition, $\mathrm{VCH}$ Verlagsgesellschaft, Weinhem Federal Republic of Germany.

Widayat dan H Satriadi, (2005), "Pembuatan Diethil Eter Dari Etanol Teknis Dengan Proses Reaktif Distilasi, Prosiding Seminar Nasional Soehadi Reksowardojo, Departemen Teknik Kimia FTI ITB, Bandung, 12 Desember 2005, ISSN: 0854-7769 